\begin{tabular}{|l|l|l|l|l|l|l|}
\hline InterteXto & Uberaba & UFTM & $\begin{array}{l}\text { v. 3 } \\
\text { n. 2 }\end{array}$ & p. 05-24 & 2010 - jul. / dez. & ISSN 1981-0601 \\
\hline
\end{tabular}

\title{
ANGOLA E SUA LITERATURA: UMA INTRODUÇÃO À PROSA DE FICÇÃO ANGOLANA LUSÓFONA
}

\author{
ANGOLA AND ITS LITERATURE: AN INTRODUCTION TO PROSE FICTION \\ ANGOLAN LUSOPHONE
}

Mauricio Silva ${ }^{1}$

Resumo: $O$ presente artigo procura analisar a relação entre identidade cultural e consciência nacionalista nas literaturas africanas lusófonas, principalmente considerando as perspectivas estética (Sartre) e moral (Marcuse). Além disso, o artigo analisa as relações entre a linguagem literária e o processo de construção da identidade cultural de Angola.

Palavras-chave: Literatura Africana Lusófona, identidade cultural, consciência nacionalista, Angola

Abstract: The presente article analyses the relations between cultural identity and reform and nationalism in the Portuguese African Literatures. Besides, it focuses those relations both from the aesthetic (Sartre) anda moralistic (Marcuse) perspectives. Furthermore, the article analyses the interaction between the literary language and the Angola's cultural identity.

Key-words: Portuguese African Literature, cultural identity, nationalism, Angola

\section{Introdução}

Não há como negar o fato de que, de certa maneira, a literatura reflete a sociedade na qual ela se encontra invariavelmente inserida. Por mais que alguns críticos e teóricos defendam a separação radical entre literatura e sociedade, há um fator determinante nessa discussão: ambas estabelecem entre si uma relação necessária de interdependência, na medida em que se trata de conceitos marcados por um sentido de reciprocidade, que resulta na interação da natureza

\footnotetext{
1 Doutor, professor e coordenador da Pós-Graduação lato sensu na Universidade Nove de Julho. maurisil@gmail.com
} 


\begin{tabular}{|l|l|l|l|l|l|l|}
\hline InterteXto & Uberaba & UFTM & $\begin{array}{l}\text { v. 3 } \\
\text { n. } 2\end{array}$ & p. 05-24 & 2010 - jul. / dez. & ISSN 1981-0601 \\
\hline
\end{tabular}

essencialmente estética da literatura com a conformação fundamentalmente política da sociedade.

Ligadas entre si de forma quase inexorável, portanto, é comum revelarem todas as contradições que lhe são inerentes, motivo pelo qual é relativamente comum percebermos na representação artística, em determinadas obras literárias, das várias incertezas, dos diversos equívocos e das múltiplas contradições do próprio tecido social. Por isso, de uma noção verdadeiramente mítica, a arte passou a ser entendida como uma manifestação autenticamente cultural, sujeito a todas as vicissitudes que esse conceito possa acarretar: a arte como realização da criatividade humana, proveniente da inspiração inacessível aos homens comuns como era entendida, por exemplo, pelos românticos -, abandonou definitivamente essa condição supra-humana para se colocar como criação da mais pura vontade do homem e da sociedade.

No caso das chamadas sociedades emergentes, como é o caso dos países africanos de expressão portuguesa, a literatura está claramente - mas, não, exclusivamente, como nas sociedades de regime totalitário - a serviço de uma determinada ideologia e, via de regra, como manifestação prática de uma causa revolucionária ou da afirmação de uma identidade. De sociedades emergentes, surgem, em geral, estéticas igualmente emergentes, isto é, expressões artísticas comprometidas com a liberdade política da sociedade em que se inserem: são manifestações artísticas em que a função social é, para além de significativa, estrutural, o que, aliás, ocorre não apenas em boa parte do continente africano, mas também numa parcela considerável da produção latino-americana (RETAMAR, 1979). Evidentemente, trata-se de um posicionamento relativamente tendencioso e, de certo modo, cronologicamente determinado, mas que, de modo bastante consciencioso, revela a necessidade de enfatizar um aspecto da literatura demasiadamente esquecido nestas épocas de globalização e 


\begin{tabular}{|l|l|l|l|l|l|l|}
\hline InterteXto & Uberaba & UFTM & $\begin{array}{l}\text { v. 3 } \\
\text { n. } 2\end{array}$ & p. 05-24 & 2010 - jul. / dez. & ISSN 1981-0601 \\
\hline
\end{tabular}

neoliberalismo a todo custo.

Fechar os olhos, portanto, à função social da literatura - sobretudo nas sociedades que aqui denominamos emergentes -, seja em virtude de um radical esteticismo, seja por uma injustificada intolerância, é negar a própria essência da expressão estética, que na sua mais íntima natureza é, antes de tudo, plural. Estética desobrigada ou mensagem comprometida, a literatura passa a ser, a um só tempo, razão e emoção, contemplação ideal e prática social, não se podendo simplesmente desconsiderar sua propriedade funcional em razão de uma suposta prevalência de aspectos estritamente imanentes e vice-versa.

Pode-se assim dizer, sem risco de cometer alguma impropriedade, que nos países africanos lusófonos, a consciência nacionalista nasce como resultado de um complexo processo de construção de uma identidade cultural, representada, entre outros, pela produção literária local. Nesse sentido, consciência nacionalista e identidade cultural são conceitos permeáveis, os quais não prescindem, como sugerimos há pouco, da concepção da arte como uma atividade socialmente engajada.

O próprio desenvolvimento da literatura africana lusófona sugere essa perspectiva crítica, na medida em que nacionalismo e identidade tornam-se conceitos fundamentais na constituição de uma literatura independente e madura, a partir do século XX. Assim, das primeiras manifestações ficcionais, ligadas ao imaginário popular e folclórico das populações nativas da região, de caráter essencialmente oral - como a ficção fantástica (mi-sosa), as estórias verídicas (maka), os feitos tribais (mi-sendu), os provérbios (ji-sabu), as poesias musicadas (mi-embu) ou as adivinhações (ji-nongongo) -, a literatura lusófona do continente africano passa por um longo processo de maturação, com uma produção, principalmente durante o século XIX, mas já avançando para o XX, ainda essencialmente colonizada - com obras como as de José Maria da Maia Ferreira 


\begin{tabular}{|l|l|l|l|l|l|l|}
\hline InterteXto & Uberaba & UFTM & $\begin{array}{l}\text { v. 3 } \\
\text { n. 2 }\end{array}$ & p. 05-24 & 2010 - jul. / dez. & ISSN 1981-0601 \\
\hline
\end{tabular}

(Espontaneidades de minha alma, 1849), José Evaristo de Almeida ( $O$ escravo, 1856), Pinheiro Chagas (Os sertões d'África, 1880), Alfredo Troni (Ngá Muturi I Senhora Viúva, 1882), Pedro Félix Machado (O Filho Adulterino, 1892), Hipólito Raposo (Ana, a Kalunga, 1926), Brito Camacho (Contos Selvagens, 1934) ou Henrique Galvão (O Velo d'Oiro, 1936) -, caracterizada, sobretudo, por uma perspectiva eurocêntrica, uma visão paternalista do negro, ao lado da mitificação do branco e da exploração do exótico. Chega, finalmente, ao longo do século XX, à sua completa maturidade, com manifestações literárias realmente nacionais e independentes - com obras como as de João Albasini (O livro da dor, 1925), Antonio de Assis Júnior (O segredo da morta, 1929/1935), Fausto Duarte (Auá, 1934), Baltasar Lopes (Chiquinho, 1947), José Luandino Vieira (Luuanda, 1964), Francisco José Tenreiro (Coração em África, 1982) e muitas outras -, cujas mais relevantes características são o anticolonialismo, a afirmação da identidade cultural, e a consciência nacionalista, ideário que se manifesta não apenas no tratamento de temas e motivos próprios da história e do cotidiano das nações representadas, mas também por uma nova ordem discursiva, que se traduz em ruptura estética e criatividade lingüística. (SANTILLI, 1985a)

Analisando o desenvolvimento da maior parte da produção literária lusófona no continente africano, não há como negar - sobretudo quando pensamos na produção mais recente - nem sua procedência anticolonialista, no plano social e histórico, nem sua vinculação quase natural com os conceitos de nacionalismo e identidade, aqui destacados. Com efeito, se essa literatura nasce vinculada a um projeto mais amplo de luta anticolonial, o que Ihe confere um caráter de literatura militante, que se utiliza do texto literário em prol de uma causa político-social independentista, com o passar do tempo e agora num plano fundamentalmente cultural, ela passa a se ligar a um desígnio identitário e nacionalista, resultando, primeiro, na afirmação da identidade cultural local, com a valorização das 


\begin{tabular}{|l|l|l|l|l|l|l|}
\hline InterteXto & Uberaba & UFTM & $\begin{array}{l}\text { v. 3 } \\
\text { n. } 2\end{array}$ & p. 05-24 & 2010 - jul. / dez. & ISSN 1981-0601 \\
\hline
\end{tabular}

singularidades nativas e comunitárias da região; e, depois, na criação de uma consciência nacionalista, incentivando a defesa de valores sociais humanitários.

Desse modo, ainda que o colonialismo tenha servido, num primeiro momento, como elemento impulsionador da consciência e da prática libertária que está na base dessa produção ficcional, como afirma Pires Laranjeira ao dizer que

o colonialismo serve-Ihe [à literatura africana] de propulsor da
consciência, a qual se rebela contra ele. No poder de confronto
dessa rebelião literária (lingüística e ideológica), no alcance da sua
ruptura, na novidade da sua inovação, é que reside o estatuto de
liberdade, da sua libertação do jugo de outras literaturas.
(LARANJEIRA, 1985, p. 10)

foi somente com a superação da condição colonial que os países africanos lusófonos puderam, definitivamente, atingir sua plena autonomia cultural:

a busca da autonomia passa, portanto, e em suma, pela
identificação dos locutores entre si e com um projeto de
independência literária face aos modelos coloniais da cultura.
Reivindicação anti-colonial, afirmação nacional, assunção étnica e
folclórica, uso do bilingüísmo textual ou de línguas não européias
(crioulo, forro, línguas bantas), exposição africanística, exaltação
rácica, exultação independentista, todos os meios são aceitáveis
pela comunidade de consciência não portuguesa, desde que
possam inserir o texto no processo de instauração de uma
comunidade africana. (LARANJEIRA, 2000, p. 243)

Há, nesse sentido, um percurso não apenas historiográfico, a alicerçar essa produção literária, mas sobretudo um percurso ideológico, que vai justamente do nativismo colonialista ao nacionalismo independentista, como a marcar idiossincraticamente - as etapas de uma produção.

Assim, num primeiro momento da formação literária africana lusófona, a que podemos chamar de Literatura Colonial (1850-1900), a marca ideológica mais relevante é justamente o conceito de nativismo, em que o elemento exótico e a perspectiva eurocêntrica - já assinaladas anteriormente - talvez sejam os 


\begin{tabular}{|l|l|l|l|l|l|l|}
\hline InterteXto & Uberaba & UFTM & $\begin{array}{l}\text { v. 3 } \\
\text { n. } 2\end{array}$ & p. 05-24 & 2010 - jul. / dez. & ISSN 1981-0601 \\
\hline
\end{tabular}

principais componentes. Nas palavras de Manuel Ferreira, nesse estágio da produção literária, "o escritor africano encontra-se em estado quase absoluto de alienação, incapaz de se libertar dos modelos europeus". (FERREIRA, s.d., p. 33) Já num segundo momento, emerge a chamada Literatura Anti-Colonial (19001930), tendo como marca ideológica mais relevante a idéia de negritude, em que a condição de escritores alienados é relativamente ultrapassada, sendo substituída pela "percepção de certo regionalismo e o discurso acusa já alguma influência do meio social, geográfico e cultural em que estão inseridos e a enunciação vive já dos primeiros sinais de sentimento nacional”. (FERREIRA, s.d., p. 33) Já na etapa da Literatura Pré-Independente (1930-1950), marcada ideologicamente pelo apego ao neo-realismo de inspiração brasileira e portuguesa, o escritor liberta-se, finalmente, de sua condição de alienado e a sua literatura "cria a sua razão de ser na expressão das raízes profundas da realidade social nacional entendida dialecticamente". (FERREIRA, s.d., p. 33) Finalmente, é na Literatura Independente (1950-2000) que o conceito de nacionalismo aflora em todo o seu vigor, consolidando uma situação em que "é de todo eliminada a dependência dos escritores africanos e restituída a sua plena individualidade". (FERREIRA, s.d., p. 33)

\section{Angola e sua literatura}

A mesma divisão feita, acima, para a expressão literária africana lusófona como um todo, serve, numa abordagem mais singularizada, para a literatura produzida em Angola: tendo conhecido uma primeira fase marcada pela expressão tipicamente colonial e nativista (com escritores como José da Silva Maia Ferreira, autor de Espontaneidade da Minha Alma, 1849; e Pedro Félix Machado, autor de O Filho Adulterino, 1892), a literatura angolana atinge um período marcado pela expressão anticolonialista (com Cordeiro da Mata, autor de 


\begin{tabular}{|l|l|l|l|l|l|l|}
\hline InterteXto & Uberaba & UFTM & $\begin{array}{l}\text { v. 3 } \\
\text { n. } 2\end{array}$ & p. 05-24 & 2010 - jul. / dez. & ISSN 1981-0601 \\
\hline
\end{tabular}

Delírios, 1877; e Alfredo Troni, com a célebre novela Senhora Viúva, 1882/1973). A fase seguinte já traz a contribuição de uma literatura pré-independentista, com o neo-realismo de um Assis Júnior (com O Segredo da Morta, 1936) e um Castro Soromenho (com Noite de Angústia, 1939; Homens sem Caminho, 1942; Calenga, 1945; Terra Morta, 1949). A literatura angolana atinge o auge de sua produção literária com uma fase que, por mais de um motivo, pode ser chamada de independente, período que se inicia sob os auspícios de um nacionalismo localista, inspirador da famosa Antologia dos Novos Poetas de Angola (1950) e, uma década depois, de poesias como as de Agostinho Neto (Poemas, 1960; Sagrada Esperança, 1974), Viriato da Cruz (Poemas, 1961), Antonio Jacinto (Poemas, 1961), Costa Andrade (Terra das Acácias Rubras, 1961), Alexandre Dáskalos (Poemas, 1961) e outros.

Poesia da melhor qualidade que se criou em Angola, essa produção concilia sentimento nacionalista e expressão lírica, buscando assim equacionar as contradições historicamente criadas por séculos de exploração colonial. Nos dizeres de Maria Aparecida Santilli,

o trabalho de construção poética consiste, assim, em avançar no re-conhecimento da identidade, pelo tatear em busca de referir-se devidamente ao referente africano/angolano, tal como este deveria estar em realidade ligado com outros. O processo poético corrige, então, a convenção cristalizada de África estática - que o poema questiona -, a partir do plural africano proposto, em oposição, portanto, ao superado conceito de continente histórica ou culturalmente monolítico. (SANTILLI, 1985b, p. 66)

No que diz respeito à prosa, além do já citado Castro Soromenho, a literatura angolana atinge sua maturidade com as obras de Arnaldo Santos (Quinaxixe, 1965), José Luandino Vieira (Luuanda, 1964; A Vida Verdadeira de Domingos Xavier, 1974; Nós, os do Makulusu, 1975; João Vêncio: os seus Amores, 1979), Mendes de Carvalho / Uanhenga Xitu (Mestre Tamoda, 1974; Bola 


\begin{tabular}{|l|l|l|l|l|l|l|}
\hline InterteXto & Uberaba & UFTM & $\begin{array}{l}\text { v. 3 } \\
\text { n. } 2\end{array}$ & p. 05-24 & 2010 - jul. / dez. & ISSN 1981-0601 \\
\hline
\end{tabular}

com Feitiço, 1974; Manana, 1974; Maka na Sanzala, 1979), Arthur Maurício Pestana dos Santos / Pepetela (As Aventuras de Ngunga, 1976; Mayombe, 1980; Yaka, 1984; A Geração da Utopia, 1992), Boaventura Cardoso (Dizanga dia Muenhu / A Lagoa da Vida, 1977), Jofre Rocha (Estórias de Musseque, 1976) e muitos outros.

Trata-se de uma produção, nos dizeres certeiros de Pires Laranjeira, em que a expressão literária

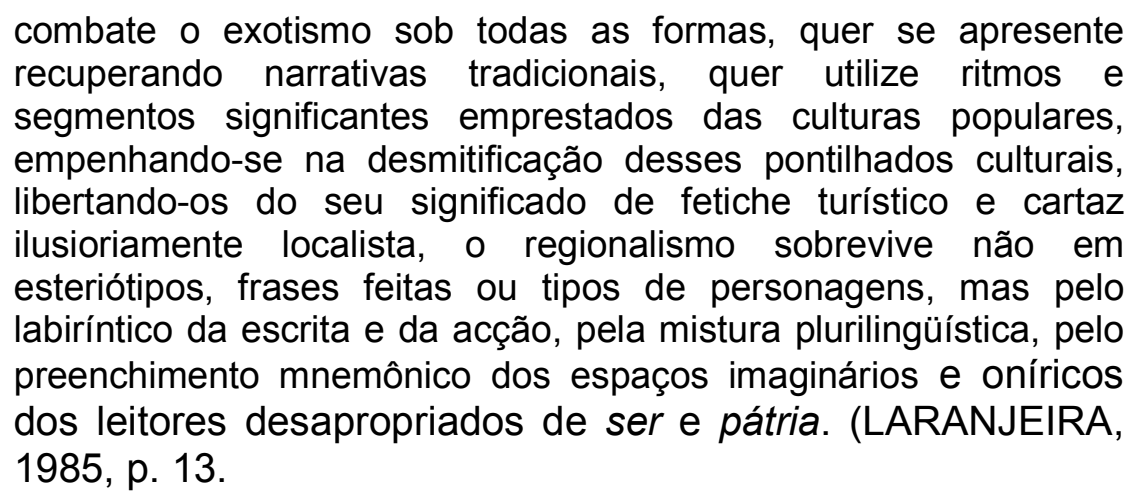

Essa é, certamente, uma opinião que define praticamente toda a literatura angolana de, pelo menos, meados do século $X X$ até os dias atuais. Se quisermos, contudo, compreender melhor essa produção, convém aproximarmos mais o foco de nossa análise e observarmos mais de perto a ficção de alguns de seus maiores autores. Três grandes nomes da literatura angolana contemporânea, representando três fases distintas, podem nos oferecer uma visão mais completa e, ao mesmo tempo, mais profunda dessa produção: José Luandino Vieira (décadas de 1960/1970), Pepetela (décadas de 1970/1980) e José Eduardo Agualusa (décadas de 1980/1990).

Luandino Vieira, autor premiado e consagrado internacionalmente, torna-se, pelo menos desde Luuanda (1964), expressão máxima da literatura angolana, tendo ainda participado ativamente da vida política de seu país, tanto como 


\begin{tabular}{|l|l|l|l|l|l|l|}
\hline InterteXto & Uberaba & UFTM & $\begin{array}{l}\text { v. 3 } \\
\text { n. } 2\end{array}$ & p. 05-24 & 2010 - jul. / dez. & ISSN 1981-0601 \\
\hline
\end{tabular}

militante clandestino nas lutas anticolonialistas quanto como membro do MPLA. Sua celebrada produção - que inclui obras como A Cidade e a Infância (1960), A Vida Verdadeira de Domingos Xavier (1961), Luuanda (1964), Velhas Estórias (1974), No Antigamente, na Vida (1974), Nós, os do Makulusu (1975), Macandumba (1978), João Vêncio e os seus Amores (1979) etc. - possui inegável valor estético-literário, além de desempenhar, sobretudo no contexto em que foi criada, relevante papel político-social, inserindo-se ainda - pelos achados criativos e pelas ousadias estilísticas - numa moderna tradição de transgressão lingüística.

É essa transgressão de natureza linguajeira, portanto, que dita o trabalho de reescritura da Língua Portuguesa levada a termo por Luandino Vieira (SILVA, 2007) e incidindo diretamente sobre a constituição de uma consciência nacionalista, já que a nova linguagem forjada no âmbito de sua produção literária acaba servindo de substrato ideológico e expressivo ao conceito de angolanidade. Com razão já se disse mais de uma vez que a linguagem empregada pelo autor de Luuanda confere à cultura nacional uma identidade própria, já que

Luandino dá a imagem da sociedade angolana em processo de
simbiose ou de influências, onde traços de diferentes culturas se
atritam e disputam primazias. Um desses traços, a fala, isto é, o
quimbundo ou o português dialetizado, por oposição à língua, o
português de Portugal, funciona também como código de
identificação no conjunto de fatores que passam a caracterizar a
angolanidade. (SANTILLI, 1985a, p. 18)

Do ponto de vista dos temas e motivos literários representados em sua obra, destaca-se, sem dúvida alguma, a temática social, sempre reconstruída a partir da ótica literária, com a exposição dos conflitos raciais e a exploração da dicotomia entre civilização (europeus) e barbárie (africanos), temas construídos a partir de uma visão deliberadamente pessimista da sociedade. Não se trata, evidentemente, de um pessimismo desalentador, que enrijece a vontade de luta e mudança, mas um pessimismo aliciante, que instiga à revolta contra as distorções 


\begin{tabular}{|l|l|l|l|l|l|l|}
\hline InterteXto & Uberaba & UFTM & $\begin{array}{l}\text { v. 3 } \\
\text { n. } 2\end{array}$ & p. 05-24 & 2010 - jul. / dez. & ISSN 1981-0601 \\
\hline
\end{tabular}

sociais apontadas na trama de suas efabulações. Não obstante essa temática densa, de uma ideologia cerrada, suas principais conquistas estéticas concentram-se no campo da estilística, já que com a prosa ficcional de Luandino Vieira a literatura angolana atinge seu ponto máximo de expressão artística, sobretudo no que diz respeito ao tratamento lingüisticamente inovador do texto literário. Tal inovação pode ser verificada tanto no âmbito sintático, levando o autor a promover verdadeira ruptura no encadeamento oracional do português, quanto nos âmbitos morfológico - com sua indefectível criatividade lexical - e fonológico, em que o emprego deliberado de uma linguagem coloquial e o uso de artifícios próprios da oralidade, incorporados ao texto escrito, fazem de suas transgressões lingüísticas uma ocorrência esteticamente programática.

Autor de obras de repercussão internacional, Pepetela (pseudônimo de Arthur Maurício Pestana dos Santos), ao lado de Luandino Vieira, redime a literatura angolana da condição de literatura periférica e colonial para alçá-la à de expressão artística de valor universal. Com obras como Yaka (1984) ou $A$ Geração da Utopia (1992), por exemplo, Pepetela consegue exprimir literariamente uma realidade onde conflitos raciais e outras formas de comprometimentos sociais são trazidos à tona, revelando a complexa e traumática herança da colonização do continente africano.

Com desprendimento e paixão, Yaka narra o conturbado relacionamento entre Angola e os colonizadores portugueses, revelando, além de tudo, uma intensa consciência histórica por parte do autor. A linguagem empregada para levar adiante essa sua denúncia procura, contudo, mesclar - como é comum à literatura de expressão africana pós-independência, a exemplo do que fez maximamente Luandino Vieira - a prosódia do colonizador (no caso, a língua portuguesa) e a do colonizado (no caso, o quimbundo), dando assim aos fatos narrados um maior realismo e, concomitantemente, elevando a obra à categoria 


\begin{tabular}{|l|l|l|l|l|l|l|}
\hline InterteXto & Uberaba & UFTM & $\begin{array}{l}\text { v. 3 } \\
\text { n. } 2\end{array}$ & p. 05-24 & 2010 - jul. / dez. & ISSN 1981-0601 \\
\hline
\end{tabular}

dos grandes livros da cultura ocidental, da qual a língua portuguesa inegavelmente faz parte.

Se em Yaka a presença da exploração comercial - emprego de mão de obra escrava, comércio protecionista e monopolizado - e da supremacia etnocultural portuguesa aparece de forma algo restrita, o mesmo não se pode dizer do racismo enquanto ideologia que fundamenta as relações sociais presentes no romance. Esse tema, ao contrário, conforma a obra por inteiro, fazendo surgir na sociedade angolana toda sorte de injustiças, como a explícita tentativa de embranquecimento da população, levada a cabo pelos colonizadores. Tal procedimento revela, no plano da narrativa, um maquiavélico projeto de erradicação da memória étnica das populações locais, submetidas, assim, a um incondicional processo civilizatório.

Discriminações mais explícitas e brutais surgem ao longo de todo o romance, exprimindo ora um sentimento de supremacia racial, que acaba por tomar conta dos colonos brancos, ora um desprezo propriamente dito pelos negros. E esses são apenas alguns exemplos do alcance da temática do racismo na obra de Pepetela, sobrepondo-se mesmo a outros temas que aparecem ao longo da narrativa: o desgosto dos colonos, quase que obrigados a viver sob o peso de um eterno desterro; as constantes ameaças que estes mesmos colonos sentem diante de uma realidade que, vez por outra, Ihes parece completamente hostil, etc. Somando isso tudo, Yaka resulta num dos mais contundentes relatos dos sofrimentos do povo angolano e numa das mais expressivas obras de literatura em língua portuguesa que o final do século $X X$ concebeu.

Já em $A$ Geração da Utopia, o que se percebe é uma bem-acabada tentativa de resgatar a história de Angola por meio da prosa de ficção. Romance histórico, no sentido mais amplo do termo, trata-se, ideologicamente falando, da busca de um sentido para a nacionalidade angolana e de uma razão para a 


\begin{tabular}{|l|l|l|l|l|l|l|}
\hline InterteXto & Uberaba & UFTM & $\begin{array}{l}\text { v. 3 } \\
\text { n. 2 }\end{array}$ & p. 05-24 & 2010 - jul. / dez. & ISSN 1981-0601 \\
\hline
\end{tabular}

consolidação de uma identidade cultural. Tematizando a crise do sistema colonial, mas sem fazer concessões a ideologias de direita e de esquerda, a projetos colonialistas ou anticolonialistas, a vencedores e a vencidos, Pepetela nos oferece um amplo retrato da história angolana, da década de 1960 até a de 1990, dividindo sua história, cronologicamente, da gestação (década de 1960) à falência (década de 1990) de um ideal utópico de construção de uma nação, sem deixar de passar por sua implantação (década de 1970) e consolidação (década de 1980).

Buscando, do ponto de vista literário, a dinamização espacial - isto é, elegendo o espaço como personagem - e a dinamização temporal - ou seja, elevando o tempo à categoria de elemento estruturador da narrativa -, A Geração da Utopia é uma das grandes obras de Pepetela, cuja produção conta ainda com romances como As Aventuras de Ngunga (1973), Mayombe (1980), Parábola do Cágado Velho (1997) e outras. Com efeito, se o tempo condiciona a subdivisão desse romance em capítulos, construídos a partir da divisão do enredo em quatro décadas distintas, o espaço ganha foros de personagem central no livro, aparecendo sob a forma diferenciada de espaço urbano (primeiro capítulo), floresta (segundo capítulo), litoral (terceiro capítulo), e espaço urbano novamente (quarto capítulo). De inspiração neo-realista (apoiando-se, portanto, tanto no neorealismo português quanto no realismo social brasileiro de 30), trata-se, como já se afirmou uma vez, do "despertar da consciência coletiva de um povo pela ênfase dada ao social". (SANTOS, 2001, p. 15)

José Eduardo Agualusa é um dos autores contemporâneos mais admirados pela crítica especializada e pelo leitor comum. Desde suas primeiras obras, narra acontecimentos relacionados não apenas á história recente de Angola, mas também ao vasto imaginário do continente africano, com sua diversidade cultural e suas ricas manifestações locais.

Em A Conjura (1989), por exemplo, história que tem como cenário a cidade 


\begin{tabular}{|l|l|l|l|l|l|l|}
\hline InterteXto & Uberaba & UFTM & $\begin{array}{l}\text { v. 3 } \\
\text { n. 2 }\end{array}$ & p. 05-24 & 2010 - jul. / dez. & ISSN 1981-0601 \\
\hline
\end{tabular}

de Luanda em 1880, discutem-se questões relacionadas à colonização portuguesa e à independência de Angola, num contexto em que se planeja uma revolta (conjura) independentista, frustrada pelo barbeiro Jerónimo Caninguili. Mesclando humor e crítica, o romance confere à linguagem um papel fundamental na composição da narrativa, trabalhando não apenas aspectos relacionados à oralidade, mas também redes intertextuais que fazem do texto um largo cenário cultural. Mas é em A Feira dos Assombrados e Outras Estórias Inverossímeis (1992) que Agualusa exercita com mais competência e ousadia faces da mística africana, misturando história e ficção, com uma narrativa de cunho memorialístico em que verdade e mentira se entrecruzam constantemente.

Livro que rapidamente ganhou repercussão dentro e fora do continente africano, Estação das Chuvas (1996) é obra em que prevalece o cunho documental, inspirada na história de Angola, mas mais uma vez mesclando fatos reais e ficcionais, caráter híbrido que só se adensa com a utilização de expedientes aparentemente avessos à narrativa ficcional (como entrevista, notas de rodapé, etc.) Revisitando ficcionalmente o movimento pela independência de Angola, Agualusa cria uma obra que - não fosse a ousadia estrutural e a ironia do tonos narrativo - enquadrar-se-ia na mais pura tradição da literatura militante, que vai, em Angola, da poesia de Agostinho Neto à prosa de Pepetela. Mas o livro mais famoso de Agualusa seria publicado no ano seguinte: com o romance epistolar Nação Crioula (1997), o romancista angolano levaria ao paroxismo os artifícios intertextuais, bem como seu já tradicional empenho em "confundir" realidade e ficção. Dialogando direta ou indiretamente com algumas célebres obras da literatura em língua portuguesa, Nação Crioula afirma-se como o desfecho de um longo percurso de construção de uma identidade marcada pela miscigenação e pela consciência crítica das relações entre os continentes americano, europeu e africano. 


\begin{tabular}{|l|l|l|l|l|l|l|}
\hline InterteXto & Uberaba & UFTM & $\begin{array}{l}\text { v. 3 } \\
\text { n. 2 }\end{array}$ & p. 05-24 & 2010 - jul. / dez. & ISSN 1981-0601 \\
\hline
\end{tabular}

Depois da publicação de obras que tornaram Agualusa escritor de renome dentro da literatura angolana, outras obras "menores" vieram se somar ao seu legado literário já consolidado, como Fronteiras Perdidas (1999), pequenos contos espirituosos, de um humorismo ágil e irônico; e A Substância do Amor e Outras Crônicas (2000), narrativas rápidas, caracterizadas pelo inesperado, pelo insólito das situações e seus desdobramentos. Do mesmo ano que este último, Um Estranho em Goa (2000) já é romance de maior fôlego narrativo, levando o autor a transformar uma experiência concreta (sua estada em Goa, região da Índia) em experiências subjetivas, internalizadas, que nascem das impressões colhidas do contato com uma realidade totalmente nova e diferente. De uma maneira um pouco mais trágica e um pouco mais realista que em outros livros, nessa obra Agualusa aborda a questão da identidade sob o prisma dos descendentes portugueses que vivem em Goa, dando ao tema um caráter mais político, mas ao mesmo tempo lírico e reflexivo, o que levaria o narrador, por exemplo, a concluir, entre outras máximas contidas no livro, que "viajar é perder pessoas". (AGUALUSA, 2001, p. 151)

Dois grandes romances - considerando a pouca repercussão de obras posteriores, como o poético e sarcástico Manual Prático de Levitação (2005) e o instável As Mulheres de meu Pai (2007) - viriam coroar a trajetória de sucesso de José Eduardo Agualusa. O Primeiro deles é o impactante $O$ Ano em que Zumbi tomou o Rio (2002), narrativa que se passa no Rio de Janeiro, com personagens brasileiros e angolanos, construída em capítulos que funcionam como se fossem pequenas cenas cinematográficas simultâneas ou que se sucedem, criando uma perspectiva fragmentada, mas que consegue se articular numa unidade temática. A obra discute mais a fundo temas de natureza racial, fazendo dialogar especialmente nesse quesito - as visões do angolano (Francisco Palmares) e do brasileiro (Jararaca). Sem dispensar o já tradicional artifício do intertexto - pelo 


\begin{tabular}{|l|l|l|l|l|l|l|}
\hline InterteXto & Uberaba & UFTM & $\begin{array}{l}\text { v. 3 } \\
\text { n. } 2\end{array}$ & p. 05-24 & 2010 - jul. / dez. & ISSN 1981-0601 \\
\hline
\end{tabular}

contrário, adensando-o -, o autor cria situações de tensão extrema, em que o diferencial pode ser, por exemplo, saber em que lado da guerra se está, levando um dos personagens à conclusão peremptória de que "nunca se esquecem as lições aprendidas na dor". (AGUALUSA, 2002, p. 81)

O outro grande romance, obra máxima dentro da premiada produção de Agualusa, é seu curioso e insólito O Vendedor de Passados (2004). Narrativa mágica - no que esta palavra pode conter de fantástico -, trata-se da história de Félix Ventura, nome sugestivo para a atividade da personagem, um vendedor de passados, isto é, um fabricante de árvores genealógicas, fotos de ancestrais, pergaminhos antigos, enfim, tudo o que possa conferir ao cliente um passado nobre. Entre idas e vindas inesperadas, discute-se não apenas aspectos da história recente de Angola, mas principalmente o impreciso conceito de identidade, já pressuposto na figura inusitada de um narrador-personagem que não é nada mais, nada menos do que uma... osga. Assim, ao escolher uma osga (espécie de lagartixa, que desempenha papel fundamental nessa discussão), o autor sugere um olhar isento de qualquer envolvimento do narrador com a essência demasiadamente humana da questão da identidade: enquanto ser irracional, deplacé, a osga está, supostamente, imune às questões "existencialistas" inscritas na trajetória dos demais personagens, a despeito de, inesperadamente, o enredo sugerir que ela teria sido, anteriormente (em outra vida?) um ser humano, carregando portanto consigo traços de uma angústia existencial, ora de alguém inutilmente à procura por um interlocutor, ora de alguém dotado de um humano remorso por não ter amado.

Assim, a cada passo da história, desdobra-se uma infinidade de possibilidades reflexivas, tornando $O$ Vendedor de Passados quase um romance filosófico, quando não existencialista, em que a identidade afirma-se como jogo de imagens refletidas em infinitos espelhos, tornando-se, portanto, um simulacro da 


\begin{tabular}{|l|l|l|l|l|l|l|}
\hline InterteXto & Uberaba & UFTM & $\begin{array}{l}\text { v. 3 } \\
\text { n. } 2\end{array}$ & p. 05-24 & 2010 - jul. / dez. & ISSN 1981-0601 \\
\hline
\end{tabular}

realidade e fazendo confundirem-se verdade e mentira, fato e ficção, essência e aparência, ser e não-ser...

Se, como diz uma personagem, "a verdade é improvável”, a fábula passa a ocupar o lugar da realidade, fazendo com que tudo se relativize e com que os pólos, aparentemente díspares, se atraiam e se igualem: "eu dou-lhe uma verdade impossível, você dá-me uma mentira vulgar e convincente". (AGUALUSA, 2004, p. 185)

\section{Conclusão}

O panorama literário aqui apresentado demonstra bem a importância da literatura africana de expressão portuguesa atualmente. É por meio de textos e autores com as mais variadas propostas estéticas que se constrói o legado literário das nações lusófonas. Evidentemente, essa produção é melhor compreendida no contexto em que se insere, mas, sem dúvida alguma, trata-se de uma literatura que tem um alcance universal, que ultrapassa os limites do continente africano e da própria língua portuguesa.

Não devemos nos esquecer, além disso, que essa literatura estabelece laços inquebrantáveis com a realidade sociocultural brasileira, sendo seu estudo particularmente propício à compreensão de nossa própria produção literária, caudatária, de certo modo, da cultura de matriz africana e de suas manifestações lingüísticas.

Essa valorização do legado cultural africano, aliás, já vem se realizando, aos poucos, por força da lei 10.639, de 2003, por meio da qual ensino da história e da cultura africana e afro-brasileira não apenas torna mais eficaz o acesso dos estudantes a informações preciosas acerca de nossa formação cultural, mas também possibilita a compreensão - que leva à consciência - da formação social brasileira. A referida lei é, sem dúvida, uma prática institucional de inclusão e de 


\begin{tabular}{|l|l|l|l|l|l|l|}
\hline InterteXto & Uberaba & UFTM & $\begin{array}{l}\text { v. 3 } \\
\text { n. 2 }\end{array}$ & p. 05-24 & 2010 - jul. / dez. & ISSN 1981-0601 \\
\hline
\end{tabular}

ação afirmativa, ao mesmo tempo em que representa o resultado de um intenso movimento de luta antirracista no Brasil, (SANTOS, 2005) destacando-se por sua capacidade multiplicadora, na medida em que pode gerar uma série de iniciativas voltadas para a valorização da cultura afro-brasileira, bem como servir de estímulo à reconstrução da identidade afro-descendente. Trata-se, em outros termos, de uma lei voltada ao resgate da auto-estima, dos valores culturais, dos direitos, da memória e da identidade do negro, desfazendo equívocos seculares e ressemantizando o conceito de negro dentro do complexo sócio-etnográfico nacional: a palavra negro expressa a noção de identidade assumida e, ao
mesmo tempo, procura subverter os significados negativos
associados a ela desde o período escravista. Em conseqüência
disso, ser negro consiste em preservar o orgulho de pertencer a
um grupo étnico cujos membros sobreviveram à exploração
escravista e trabalharam para participar da vida social do país.
(PEREIRA \& WHITE, 2001, p. 259)

Portanto, passa a ser papel de todo educador a luta incondicional pela superação do racismo e da discriminação racial, e a lei 10.639 talvez seja um dos caminhos mais eficazes para que esse ideal possa ser alcançado.

Além dessa questão pedagógica, por assim dizer, estudar as manifestações literárias africanas pressupõe ainda a elaboração de uma ampla reflexão sobre a questão do nacionalismo e da identidade na literatura, conceitos largamente presentes nos autores e obras aqui citados, bem como na maior parte da produção literária africana mais recente. Desse modo, nacionalismo e identidade acabam sendo noções que, embora em contínua transformação, aparecem problematizados na representação literária dos países estudados, via de regra associando-se a um claro pendor militante e engajado, apesar de presentes também numa expressão mais larga, de cunho existencialista e introspectivo (LARANJEIRA, 1997). Isso, evidentemente, sem se esquecer dos 


\begin{tabular}{|l|l|l|l|l|l|l|}
\hline InterteXto & Uberaba & UFTM & $\begin{array}{l}\text { v. 3 } \\
\text { n. } 2\end{array}$ & p. 05-24 & 2010 - jul. / dez. & ISSN 1981-0601 \\
\hline
\end{tabular}

experimentalismos formais e do trabalho minucioso que se tem feito com a linguagem, a qual passa a representar, na produção mais recente, uma etapa de superação de seu viés marcadamente ideológico (HAMILTON, 1981).

Esse é, portanto, um percurso ideológico de muitas faces, mas no qual se afirmam pelo menos duas idéias recorrentes: o imperativo moral e o imperativo estético.

O primeiro provém da tese, defendida por Sartre, de que a literatura voltase, entre outras coisas, para a defesa de valores sociais da humanidade, associando-se, assim, à prática libertária, seja ela relacionada ao autor, ao leitor ou à sociedade como um todo. Nesse sentido, a literatura - e esta é uma correlação bastante apropriada à literatura africana lusófona - traduz-se numa tomada de posição daqueles que com ela estejam diretamente envolvidos (SARTRE, 1989). O segundo provém das idéias expostas por Marcuse, segundo as quais a arte se manifestaria em meio às relações sociais e possuiria um potencial político, mas, ao contrário da ortodoxia marxista, ele estaria contido nela mesma, na sua dimensão estética, concorrendo, dessa forma, para a defesa da liberdade (MARCUSE, 1981).

Em ambas as teorias, a arte - exatamente como tem ocorrido nos melhores exemplos da produção lusófona em África - estaria visceralmente relacionada à idéia de liberdade, mas enquanto para Sartre ela se revela como um imperativo moral, para Marcuse, ela se manifesta como um imperativo estético.

De qualquer maneira, podemos dizer sem exagero que a literatura africana lusófona - como as melhores manifestações literárias conhecidas - se opõe visceralmente ao imaginário negativo de que o continente africano foi sempre vítima, resgatando o que o povo africano tem de melhor a oferecer: sua cultura, suas crenças, sua personalidade, seu imaginário, tudo transformado na mais sublime matéria artística. Para que percebamos esse fato, basta que saibamos ver 


\begin{tabular}{|l|l|l|l|l|l|l|}
\hline InterteXto & Uberaba & UFTM & $\begin{array}{l}\text { v. 3 } \\
\text { n. } 2\end{array}$ & p. 05-24 & 2010 - jul. / dez. & ISSN 1981-0601 \\
\hline
\end{tabular}

a realidade tal e qual ela se nos apresenta, destituídos de qualquer preconceito e estereótipo. Pois, como afirmou o angolano Pepepela, em seu magistral romance, A Geração da Utopia, "os raios de sol sempre descobrem as faces escondidas do diamante, mesmo se enterrado na areia. É só preciso saber ver". (PEPETELA, 2000, p. 101)

\section{Referências}

AGUALUSA, José Eduardo. Um Estranho em Goa. Rio de Janeiro: Gryphus, 2001, p. 151.

AGUALUSA, José Eduardo. O Ano em que Zumbi tomou o Rio. Rio de Janeiro: Gryphus, 2002, p. 81.

AGUALUSA, José Eduardo. O Vendedor de Passados. São Paulo: Companhia das Letras, 2004, p. 185.

FERREIRA, Manuel. O Discurso no Percurso Africano I (Contribuição para uma Estética Africana). Lisboa: Plátano, s.d., p. 33.

HAMILTON, Russel G. Literatura Africana. Literatura Necessária: Angola. Lisboa: Edições 70, 1981, p. 29.

LARANJEIRA, Pires. Literatura Calibanesca. Porto: Afrontamento, 1985, p. 10.

LARANJEIRA, Pires. "Língua e Literatura nos Países Africanos de Língua Oficial Portuguesa". In: GALANO, Ana Maria et alii (orgs.). Língua Mar: Criações e Confrontos em Português. Rio de Janeiro: Funarte, 1997, p. 83-99.

LARANJEIRA, Pires. "As Literaturas Africanas de Língua Portuguesa - Identidade e Autonomia" Scripta, Belo Horizonte. Vol. 03, No. 06: 237-244, 2000, p. 243. MARCUSE, Herbert. A Dimensão Estética. São Paulo: Martins Fontes, 1981. PEPETELA. A Geração da Utopia. Rio de Janeiro: Nova Fronteira, 2000, p. 101. PEREIRA, Edimilson de Almeida e WHITE, Steven F. "Brasil: Panorama de 


\begin{tabular}{|l|l|l|l|l|l|l|}
\hline InterteXto & Uberaba & UFTM & $\begin{array}{l}\text { v. 3 } \\
\text { n. 2 }\end{array}$ & p. 05-24 & 2010 - jul. / dez. & ISSN 1981-0601 \\
\hline
\end{tabular}

Interações e Conflitos numa Sociedade Multicultural". Afro-Ásia. Centro de Estudos Afro-Orientais/Universidade Federal da Bahia, Salvador, No. 25/26: 257280, 2001, p. 259

RETAMAR, Roberto Fernández. "Intercomunicação e Nova Literatura". In: MORENO, César Fernández (coord.). A America Latina em sua Literatura. São Paulo: Perspectiva, 1979, p. 325-339).

SANTILLI, Maria Aparecida. Estórias Africanas. História e Antologia. São Paulo: Ática, 1985a

SANTILLI, Maria Aparecida. Africanidade. Contornos Literários. São Paulo: Ática, 1985b

SANTOS, Francisca Maria dos. Quarup e A Geração da Utopia: História Ficção e Utopia. São Paulo, FFLCH/USP, 2001 (Dissertação de Mestrado), p. 15. SANTOS, Sales Augusto dos. "A Lei 10.639/03 como Fruto da Luta Anti-Racista do Movimento Negro". In: MINISTÉRIO DA EDUCAÇÃO, SECRETARIA DE EDUCAÇÃO CONTINUADA, ALFABETIZAÇÃO E DIVERSIDADE. Educação AntiRacista: Caminhos Abertos pela Lei Federal n 10.639/03. Brasília, 2005, p. 21-37. SARTRE, Jean-Paul. Que é Literatura? São Paulo: Ática, 1989.

SILVA, Maurício. "A Tradição da Transgressão: Língua Portuguesa e a Identidade Cultural em Luandino Vieira". Scripta. Pontifícia Universidade Católica de Minas Gerais, Belo Horizonte, V. 11, No. 20: p. 167-176, 2007. 